\title{
A IMPORTÂNCIA DAS FERRAMENTAS DE MARKETING DE RELACIONAMENTO PARA O PROFISSIONAL DE SECRETARIADO EXECUTIVO
}

\section{THE IMPORTANCE OF RELATIONSHIP MARKETING TOOLS FOR THE EXECUTIVE SECRETARIAT PROFESSIONAL}

\section{Tatyane Neves Marum}

Graduada em Secretariado Executivo Trilíngue pela Fundação Escola de Comércio Álvares Penteado (FECAP). E-mail: tatyane.marum@edu.fecap.br (Brasil)

\section{Iná Futino Barreto}

Doutora em Administração pela Faculdade de Economia, Administração e Contabilidade (FEA/USP) e Professora na Fundação Escola de Comércio Álvares Penteado (FECAP). Email: ina.barreto@fecap.br (Brasil)

\section{Rodolfo Rodrigues Rocha}

Mestrando em Administração de Empresas na Faculdade de Economia, Administração e Contabilidade (FEA/USP). E-mail: rodolfo.rocha@gmail.com (Brasil) 


\title{
A IMPORTÂNCIA DAS FERRAMENTAS DE MARKETING DE RELACIONAMENTO PARA O PROFISSIONAL DE SECRETARIADO EXECUTIVO
}

\section{RESUMO}

O perfil profissional ideal de um secretário executivo atualmente contempla conhecimentos e habilidades variados. Entre esses estão as ferramentas de Marketing de Relacionamento destacadas neste estudo. Por estar em contato constante com os clientes da empresa, o secretário executivo troca informações importantes com eles. Esse papel de interface de comunicação pode ser valioso para a empresa, caso o profissional de Secretariado Executivo esteja apto a exercê-lo corretamente. Com essa preocupação em mente, o objetivo desta pesquisa foi discutir a importância dos conhecimentos das ferramentas de Marketing de Relacionamento para os profissionais de Secretariado Executivo na perspectiva dos gestores na cidade de São Paulo. Para a elaboração deste trabalho foram realizadas entrevistas em profundidade utilizando um roteiro elaborado com base no referencial teórico levantado para o presente estudo. As entrevistas, gravadas e transcritas foram analisadas com a abordagem qualitativa. Como resultado, foi possível observar que a relação da empresa com os clientes é beneficiada quando o secretário executivo possui conhecimentos sobre Marketing de Relacionamento. $\mathrm{Na}$ opinião dos executivos entrevistados, empresas que contam com secretários executivos que atuam como filtro de informações e conhecem as ferramentas de Marketing de Relacionamento, podem obter vantagem em relação a seus concorrentes.

Palavras-chave: Marketing de Relacionamento. Secretariado Executivo. Fidelização.

\section{THE IMPORTANCE OF RELATIOSHIP MARKETING TOOLS FOR THE EXECUTIVE SECRETARIAT PROFESSIONAL}

\begin{abstract}
The ideal profile of an Executive Secretary includes multiple knowledge and skills nowadays. Among them, Relationship Marketing tools, which are the object of this research. Due to being in constant contact with company's customers, the Executive Secretary exchanges important information with them. This communication interface role can be valuable to the company if the Executive Secretariat professional can execute it properly. The objective of this paper was to discuss the importance of the Relationship Marketing tools for the Executive Secretariat professionals on the perspective of managers in the city of São Paulo. In order to achieve this goal, we have conducted in-depth interviews with a script based on theoretical framework used in this research. The interviews, after being recorded and transcribed, were analyzed according to the qualitative approach. As a result, we could observe that the company's relationship with customers is benefited when the Executive Secretary knows about Relationship Marketing. According to the managers interviewed, companies concerned with the customers loyalty, and which employ Executive Secretaries with knowledge of Relationship Marketing tools working as information filter, can get advantage over competitors.
\end{abstract}

Keywords: Relationship Marketing. Executive Secretariat. Loyalty. 


\section{INTRODUÇÃO}

O profissional de Secretariado Executivo ocupa, hoje, uma posição estratégica ao lado do poder decisório de uma organização, o que lhe outorga grande responsabilidade. $O$ secretário executivo criativo e multifuncional vem se destacando no mercado de trabalho, fazendo com que as empresas cada vez mais busquem perfis com conhecimentos específicos e visão empreendedora, inovadora e competitiva (Gonçalves, 2007). Segundo o autor, atualmente, o secretário executivo possui um perfil que se preocupa com o todo empresarial, com a produtividade e com os lucros da empresa, tornando-se um profissional eficaz, negociador, participativo e competitivo. Fica claro, portanto, que se torna cada vez mais central para o trabalho de secretário executivo o conhecimento de ferramentas de gestão e administração. Dentre as diversas funções administrativas, este trabalho tem seu foco no Marketing, especificamente, no Marketing de Relacionamento.

O foco em Marketing se justifica, pois, de acordo com Silva e Gubert (2004), vivemos a era do Marketing, tanto no âmbito organizacional quanto na área profissional. Esses profissionais encontram-se em um ambiente totalmente novo e diferenciado. Uma das principais diferenças que se destaca no cenário atual é a grande preocupação no relacionamento entre empresa e cliente. De acordo com Pavoni, Rocha, Vendrame, Sarraceni e Vendrame (2009), historicamente, as organizações não demonstravam interesses no relacionamento com o cliente. Segundo os autores, o principal objetivo era a produção, porém, com o passar do tempo, percebeu-se a necessidade de profissionais com competências técnicas para reforçar a relação da empresa com o cliente, procurando estabelecer relações duradouras por meio da satisfação.

O Marketing de Relacionamento pode ser entendido como resultado dessa tendência. Segundo Barreto e Crescitelli (2013), o Marketing de Relacionamento é uma resposta às mudanças que ocorrem no mercado. Nesse contexto, pode ser entendido como a gestão de relacionamentos, busca pelo fortalecimento de relações e o contínuo aprimoramento de produtos e serviços com base no feedback expresso por um público que é cada vez mais exigente e envolvido com as marcas e as empresas (Barreto, Crescitelli \& Figueiredo, 2015). Assim, Pahins e Carvalho (2015) explicam que frente a esses consumidores com maior poder de voz, as empresas definem novas formas de relacionamento com seu público. Em consequência, os autores afirmam que as empresas se beneficiam desse envolvimento, buscando informações e feedbacks que são utilizados de forma estratégica, visando melhorias no processo produtivo, geração de inovações e lucro.

Pode-se considerar que o Marketing de Relacionamento surge como uma nova modalidade no âmbito organizacional, que visa estabelecer e desenvolver um bom relacionamento da empresa com os clientes. Ao mesmo tempo, destaca-se a importância do conhecimento de ferramentas de gestão por parte dos profissionais de Secretariado Executivo. Diante desse contexto, discutimos neste estudo a importância das ferramentas de Marketing de Relacionamento para o profissional de Secretariado Executivo na perspectiva dos gestores na cidade de São Paulo.

De acordo com Zanon e Martins (2013), a pesquisa no secretariado é algo novo para professores, pesquisadores, alunos e profissionais da área, em especial se for levado em consideração que até no ano de 2008 as publicações eram mais focadas na atuação profissional, sem o objetivo de estudar o profissional de secretariado com foco nos conhecimentos e especificidades da área. Ao analisar esse novo cenário, Silva e Gubert (2004) observam que o mercado está cada vez mais exigente, em todos os sentidos. Os autores afirmam que, para o profissional de secretariado, quanto mais conhecimentos multidisciplinares tiver, sobretudo na área de Marketing e do relacionamento específico com os clientes, mais condições terá para contribuir com o sucesso da empresa. 
Dessa forma, esta pesquisa busca contribuir suprindo a carência de estudos científicos abordando as especificidades da profissão de secretário executivo, discutindo a mudança no perfil exigido, cada vez mais multidisciplinar e inserido na realidade de gestão da empresa, sem deixar de observar a crescente importância do Marketing de Relacionamento e, mais especificamente, da relação de longo prazo entre empresa e cliente.

\section{FUNDAMENTAÇÃO TEÓRICA}

O presente artigo está fundamentado em dois conceitos principais: Marketing de Relacionamento e Secretariado Executivo. Discutir a relação entre os dois conceitos também é proposta desta seção.

\subsection{Marketing de relacionamento}

O Marketing de Relacionamento pode ser considerado uma das mais novas escolas dentro da área de Marketing, contestando algumas teorias tradicionais da área (Khan, 2014). Todas as atividades que envolvem estabelecer, desenvolver e manter relações de troca com os clientes interessam aos profissionais da área de Marketing de Relacionamento e também aos pesquisadores que abordam esse tema (Marshall, 2010).

Barreto e Crescitelli (2013) afirmam que o principal objetivo das estratégias do Marketing de Relacionamento é agregar valor para os clientes, e, dessa maneira, construir um longo, mútuo e rentável relacionamento com eles. Assim, ao invés de buscar participação de mercado, o objetivo do Marketing de Relacionamento é a participação no cliente, identificando o maior número de necessidades em cada um deles (Peppers \& Rogers, 2001).

Para que as estratégias de Marketing de Relacionamento obtenham sucesso, é necessário fazer uma análise do mercado para que as empresas conheçam muito bem seus clientes, seus concorrentes, e também analisem cuidadosamente o seu mix de Marketing, para assim obter vantagem competitiva, com foco na relação com seus clientes (Barreto \& Crescitelli, 2013). Os autores afirmam que, por meio dessa análise de mercado, as organizações têm a possibilidade de projetar e lançar ações voltadas para seus clientes, fazendo com que eles se tornem cada vez mais próximos e rentáveis.

Para Berry (1995), os elementos essenciais do Marketing de Relacionamento são:

Desenvolver um serviço principal sobre o qual será construído um relacionamento; personalizar o relacionamento para clientes individuais; ampliar o serviço principal com benefícios extras; precificar para estimular a lealdade do cliente; e comunicar-se com os empregados para que eles, em contrapartida, tenham melhor desempenho com os clientes. (p. 236)

Granero (2008) afirma que Marketing de Relacionamento é construir e sustentar a estrutura dos relacionamentos com os clientes, com a integração dos clientes com a empresa, desde o projeto e desenvolvimento de processos até as vendas. Trata-se de garantir a satisfação contínua e o reforço aos indivíduos ou organizações que são clientes por meio da identificação, reconhecimento, comunicação e feedback de uma forma geral e personalizada (Granero, 2008). 


\subsection{A importância do marketing de relacionamento}

Para Zenone (2010), uma empresa que deseja obter bons relacionamentos no mercado competitivo precisa ter bem mais do que preços competitivos ou um bom produto; o ponto mais importante é manter o foco no mercado e um gerenciamento eficiente e eficaz do atendimento ao cliente. A ideia de gestão do relacionamento com o cliente surge no fim da década de 1980 por conta, principalmente da crise energética americana, do crescimento da importância do setor de serviços e das mudanças nas relações de parcerias com fornecedores no mercado B2B (Sheth, 2002).

O destaque dessa nova modalidade do Marketing é criar valor pela intimidade com o cliente, fazendo com que a oferta seja tão adequada a ponto de o cliente preferir se manter fiel à mesma empresa (Peppers \& Rogers, 2001). Essa maior interação com os clientes tem o objetivo de agregar valor, gerando maior fidelização, que resultará em um sucesso competitivo e sustentável para o negócio (Zenone, 2010). Todo esse cenário tem sido transformado pelo avanço da tecnologia da informação, que trouxe a ideia de CRM Customer Relationship Manegement (Sheth, 2002). Payne e Frow (2005) afirmam que, muitas vezes, CRM se confunde com Marketing de Relacionamento, mas o primeiro está mais relacionado ao uso da tecnologia da informação como ferramenta de Marketing de Relacionamento.

Barreto et al. (2015), afirmam que um ponto importante para empresa e cliente atingirem valor em seu relacionamento é que a empresa não somente atenda seus clientes de uma forma diferenciada, mas sim que supere as expectativas e consiga optar por trabalhar com os clientes que tenham um maior potencial e sejam mais rentáveis a longo prazo. Para os autores, existem os clientes mais lucrativos e os menos lucrativos. Cabe à empresa saber identificar os clientes mais lucrativos para que, dessa maneira, possa oferecer um tratamento superior a eles (Sheth, 2002).

\subsection{Características do marketing de relacionamento}

Barreto e Crescitelli (2013), destacam os três principais pontos que caracterizam o Marketing de Relacionamento:

a) personalizar o relacionamento para clientes individuais: personalizar o relacionamento para clientes individuais é direcionar o trabalho de marketing para cada cliente individual e não para a massa, como acontece tradicionalmente;

b) oferecer benefícios extras: oferecer alguma vantagem, como um diferencial que fidelize o cliente para continuar comprando seus produtos;

c) comunicar-se com os funcionários: o processo de Marketing de Relacionamento só terá resultado satisfatório se todos os funcionários estiverem devidamente envolvidos no processo.

Mendes (2015) descreve o que considera as seis principais características do Marketing de Relacionamento da seguinte forma:

a) busca da integração do cliente ao processo de planejamento dos produtos e serviços, para garantir a satisfação dos desejos e necessidades que eles anseiam;

b) desenvolvimento da empresa em relação aos nichos de mercado, canais de distribuição e identificação de segmento; 
c) desenvolvimento de infraestrutura com os influenciadores, objetivando criar a imagem da empresa e o desenvolvimento tecnológico;

d) desprendimento de esforços mercadológicos e tempo com os clientes, buscando monitorar as mudanças do ambiente competitivo;

e) monitoramento constante da concorrência, a fim de prever as mudanças nas condições futuras da indústria, onde os prováveis movimentos dos concorrentes demonstrarão suas intenções e a capacidade de responder a tais mudanças;

f) desenvolvimento de um sistema de análise mercadológica, buscando sempre obter um retorno de informações para que se possam tomar as decisões em tempo hábil, proporcionando, portanto, um processo contínuo de adaptações às constantes mudanças do ambiente competitivo.

As empresas precisam ampliar sua visão de atendimento, mobilizando esforços em equipe (Khan, 2014), onde o secretário executivo está incluído, além de utilizar meios de comunicação eficazes, para que se obtenha reconhecimento imediato do cliente (Payne \& Frow, 2005). Dessa forma, o profissional de secretariado também deverá ser envolvido no processo de Marketing de Relacionamento. Cabe, portanto, aprofundar o entendimento sobre o profissional de Secretariado Executivo para que seja possível identificar sua importância para o Marketing de Relacionamento.

\subsection{Secretariado Executivo}

Para Azevedo e Costa (2000), ser um secretário executivo é ser um profissional atualizado com tudo que está ao seu redor. Um profissional dinâmico, ágil, criativo e totalmente conectado às novas tecnologias, essas são as características esperadas do secretário executivo do século XXI.

Com essas competências, o profissional está apto a fazer a conexão entre cliente e empresa, e vice-versa. Camargo (2013) ressalta a necessidade crescente de as empresas buscarem profissionais com qualidade, empatia e confiabilidade. Ainda segundo o autor, para exercer a profissão de secretário executivo hoje, o profissional deve possuir habilidades e características essenciais à profissão, além de ter a formação superior, especialização na área e estar em constante atualização.

Um profissional dessa área precisa ser versátil e competente para realizar diversas tarefas simultaneamente. Nesse contexto, destaca-se a visão sistêmica do secretário executivo que, segundo Rauber e Rauber (2013), é a necessidade de o profissional conhecer o todo, sabendo da importância das partes dentro da organização na qual está inserido. E é justamente essa proposta do curso de Secretariado Executivo: fazer com que o conhecimento e a visão sistêmica capacitem o profissional para lidar com qualquer situação que the for apresentada, pois os secretários executivos têm uma formação rica em técnicas secretariais, línguas estrangeiras, Marketing, Economia, entre outras disciplinas. (Rauber \& Rauber, 2013).

Com essa ampla formação, o secretário executivo é um profissional de perfil adequado para assessorar, solucionar problemas, delegar tarefas a terceiros etc., para que desta maneira seja visto no contexto corporativo como peça fundamental para produzir as mudanças que são exigidas dentro e fora das organizações (Bíscoli \& Lotte, 2006). 


\subsection{Funções de um secretário executivo}

Guimarães (2001) afirma que as funções de um secretário executivo invadem a área do Marketing, Administração, Recursos Humanos, Finanças, Matemática Financeira e Qualidade. Essa ampla relação com diversas áreas pode se explicar pelo próprio campo de atuação do secretário executivo. Segundo Decker (2010), o secretário encontra seu campo de atuação em um cenário de seletividade e de competitividade, muitas vezes atuando como gestor e empreendedor em empresas públicas e privadas de pequeno, médio e grande porte.

Algumas das funções que são exercidas pelo profissional de secretariado são: controle de agendas e compromissos dos executivos, planejamento de viagens, pagamentos de contas, elaboração de relatórios mensais e suporte no desenvolvimento da organização (Mazulo \& Liendo, 2010). Porém, para que isso ocorra de uma maneira bem-sucedida, os autores afirmam que é necessário que o secretário tenha uma ampla visão da empresa para poder desenvolver ações de liderança, motivação, comunicação efetiva, criatividade e negociação no ambiente organizacional.

Para Silva e Gubert (2004), o profissional de Secretariado Executivo será a interface empresa-executivo e mercado-empresa. Produzindo uma análise da nova conjuntura e reconhecimento desse profissional, os autores apontam que secretários, além de suas funções básicas, podem ajudar executivos e colocar sua atenção no que é significativo para os negócios. Assim, o secretário executivo pode coordenar todo o processo de informação, para que os executivos recebam as informações com qualidade e direcionadas para soluções, decisões e resultados. Mazulo e Liendo (2010) reforçam essa questão, destacando que, hoje, o secretário ocupa o papel de assessor de seu executivo. Assim, necessita conhecer as mesmas técnicas utilizadas por ele em seu dia a dia para poder compreender suas ações e decisões.

Considerando o secretário executivo como ponto de contato com os clientes, esse profissional pode ser bastante útil para perceber e reportar o que Biswas (2016) chama de sinais do relacionamento. $\mathrm{O}$ autor coloca essa função no contexto gerencial, mas, como o secretário executivo pode ser considerado o assessor do executivo, nada mais natural que ele também desempenhe esse papel.

Para exercer as funções de secretário executivo são necessárias habilidades humanas e competências técnicas. São essas habilidades facilitarão a compreensão dos processos organizacionais e a integração cliente-fornecedor. Em um contexto bastante competitivo, que é o caso do Secretariado Executivo atual, destacam-se os profissionais que conquistam e desenvolvem essas habilidades e competências, e que estejam comprometidos com a qualidade de seus serviços (Decker, 2010).

\subsection{Marketing de relacionamento versus secretário executivo}

Silva e Gubert (2004) conceituam que o novo modelo econômico demanda diferente perfil empresarial e profissional, que demanda, além de maior qualificação dos trabalhadores, maior envolvimento emocional e social das empresas. Neiva e D'Elia (2009) afirmam que maiores responsabilidades e conhecimentos outorgarão mais poder ao secretário executivo em processos decisórios, efetuando contato com outros níveis hierárquicos e operacionalizando com maior eficiência as comunicações horizontais e verticais dentro da organização. Isso, segundo as autoras, fará com que os executivos se libertem de rotinas que demandam bastante tempo, ampliando espaço para supervisão e controle de metas, por exemplo.

Um secretário executivo precisa ter uma visão global da organização para que haja uma total interação e harmonia na execução das tarefas (Silva \& Gubert, 2004). E, nesse contexto, o profissional cumprirá a missão de um executivo de serviços, despontando como 
base fundamental de alavancagem de departamentos, setores, divisões e áreas dentro da organização (Neiva \& D'Elia, 2009).

Considerando que o profissional de Secretariado Executivo precisa ter uma visão global da organização (Silva \& Gubert, 2004) e que as principais características do Marketing de Relacionamento são personalizar o relacionamento com clientes individuais, oferecer benefícios extras e manter a comunicação com os funcionários (Barreto \& Crescitelli, 2013), fica claro que será útil que o secretário executivo compreenda as funções do Marketing de Relacionamento. Perceber e reportar os sinais de relacionamento (Biswas, 2016) é outro papel gerencial de Marketing de Relacionamento que o secretário executivo poderia passar a desempenhar, mesmo que de forma auxiliar, e que contribuiria para a organização.

O secretário executivo que conheça as ferramentas de Marketing de Relacionamento está apto a receber informações passadas pelos clientes através dos meios de comunicação com a empresa e processá-las para saber o que deve ser levado ao conhecimento do executivo, ter acesso às informações do mercado e da concorrência e filtrar os pontos mais importantes que devem ser repassados para o executivo, e influenciar as decisões de relacionamento com o cliente que serão repassadas aos demais funcionários da empresa por meio da comunicação interna.

\section{MÉTODO}

O presente estudo é de natureza exploratória que, segundo Malhotra (2005), tem como objetivo investigar ou examinar um problema para proporcionar conhecimento e compreensão, alinhado ao objetivo deste estudo que é discutir a importância das ferramentas de Marketing de Relacionamento para o profissional de Secretariado Executivo.

A abordagem qualitativa escolhida para esta pesquisa está alinhada à definição de Denzin e Lincoln (2011) para pesquisa qualitativa que é a que dá ênfase nas entidades, nos processos e significados que não são examinados por experimentos ou medidos em termos de quantidade, amostra, intensidade ou frequência.

Pode-se caracterizar este estudo também como uma pesquisa aplicada, pois tem fins práticos e concretos, ou seja, projetada para aplicar suas descobertas a um problema específico (Collis \& Hussey, 2005), no caso, discutir a importância das ferramentas de Marketing de Relacionamento para o profissional de Secretariado Executivo.

A técnica de coleta de dados utilizada foi entrevista em profundidade, com o uso de um roteiro estruturado que será detalhado a seguir. A proposta das entrevistas foi captar a visão deles em relação à importância das ferramentas de Marketing de Relacionamento para os profissionais de Secretariado Executivo. Todas as entrevistas foram gravadas e transcritas para auxiliar a análise.

As entrevistas foram realizadas com cinco gestores de quatro empresas de pequeno e médio porte da cidade de São Paulo. O critério de seleção das empresas e seus respectivos executivos pautou-se pela conveniência dos pesquisadores, e pode ser considerada não probabilística, já que o presente estudo não pretende generalizar os resultados da pesquisa para toda a população.

Assim, foram selecionadas as seguintes empresas: Track \& Field (moda esportiva), Meiry Kamia Consultoria (palestras e treinamentos empresariais), Dentsply (equipamentos odontológicos) e Fecap - Fundação Escola de Comércio Álvares Penteado (ensino). Da Fecap, foram entrevistados dois gestores. Dos cinco entrevistados, dois foram homens e três, mulheres. Para preservar o anonimato dos entrevistados, optamos por não divulgar seus 
nomes. Essa decisão não compromete a análise, pois não se pretende observar casos individuais.

\section{Instrumento de coleta}

Hair, Babin, Money e Samouel (2005), conceituam que o tipo e a quantidade de dados a serem coletados dependem da natureza do estudo e dos objetivos da pesquisa. Para eles, quando o estudo é exploratório, o pesquisador pode coletar dados narrativos, por meio de grupos de focos ou entrevistas pessoais, por exemplo. Ainda segundo os autores, as abordagens qualitativas para coletas de dados são típicas do estudo exploratório, ajudando a elaborar e testar estruturas conceituais.

Neste estudo, foi utilizado um roteiro de entrevistas desenvolvido e fundamentado nos conceitos teóricos apresentados anteriormente. Esse roteiro, com cada pergunta e sua respectiva fundamentação teórica e fonte, é apresentado na Figura 1.

\section{ANÁLISE DOS DADOS}

Nesta seção, são apresentados os resultados das entrevistas realizadas com os gestores que captou a visão deles em relação à importância das ferramentas de Marketing de Relacionamento para os profissionais de Secretariado Executivo. Cada questão do roteiro de entrevista apresentado na Figura 1 será analisada individualmente, com uma breve discussão sobre as respostas obtidas.

\section{Figura 1 - Roteiro de entrevista}




\begin{tabular}{|c|c|c|}
\hline Pergunta & Fundamentação Teórica & Fonte \\
\hline \multirow[t]{2}{*}{$\begin{array}{l}\text { 1. Quais as principais funções do secretário executivo em sua } \\
\text { empresa? }\end{array}$} & \begin{tabular}{|} 
O secretário executivo, entre suas \\
atribuições, coordena todo o \\
processo de informação que chega \\
aos níveis decisórios para que eles \\
a recebam com qualidade.
\end{tabular} & Silva e Gubert (2004) \\
\hline & $\begin{array}{l}\text { O secretário ocupa o papel de } \\
\text { assessor de seu executivo. }\end{array}$ & $\begin{array}{c}\text { Mazulo e Liendo } \\
\text { (2010) } \\
\end{array}$ \\
\hline $\begin{array}{l}\text { 2. Quais as habilidades humanas e competências técnicas } \\
\text { considera necessárias para o secretário executivo em sua } \\
\text { empresa? }\end{array}$ & \begin{tabular}{|c|} 
São essas habilidades que irão \\
facilitar a compreensão e \\
importância de seus processos e da \\
integração cliente-fornecedor.
\end{tabular} & Decker (2010) \\
\hline $\begin{array}{l}\text { 3. Você considera necessário que o secretário executivo tenha } \\
\text { uma ampla visão da empresa? Por quê? }\end{array}$ & \multirow{2}{*}{\begin{tabular}{|c|} 
No cenário de grande \\
competitividade é necessário que o \\
profissional compreenda o ambiente \\
de negócios em que está inserido. \\
\end{tabular}} & \multirow{2}{*}{ Gonçalves (2007) } \\
\hline 4. Se sim, de que forma a empresa incentiva isso? & & \\
\hline $\begin{array}{l}\text { 5. Marketing de Relacionamento é construir e sustentar a } \\
\text { infraestrutura dos relacionamentos de clientes. É a integração } \\
\text { dos clientes com a empresa, desde o projeto, desenvolvimento } \\
\text { de processos e de vendas. Trata-se de garantir a satisfação } \\
\text { contínua e reforço aos indivíduos ou organizações que são } \\
\text { clientes através da identificação, reconhecimento, comunicação } \\
\text { e feedback, de uma forma geral e personalizada. A partir } \\
\text { desse pressuposto, você considera que pode ser benéfico que } \\
\text { o secretário executivo tenha conhecimentos de Marketing de } \\
\text { Relacionamento? Por quê? }\end{array}$ & $\begin{array}{l}\text { Relação entre o Marketing de } \\
\text { Relacionamento e o Secretário } \\
\text { Executivo. }\end{array}$ & $\begin{array}{l}\text { Barreto e Crescitelli } \\
\text { (2013); Gonçalves } \\
\text { (2007); Granero } \\
\text { (2008) }\end{array}$ \\
\hline $\begin{array}{l}\text { 6. O secretário executivo da sua empresa de alguma forma age } \\
\text { como um filtro da informação recebida por você? Se sim, de } \\
\text { que forma? }\end{array}$ & \multirow{6}{*}{$\begin{array}{l}\text { O secretário executivo, entre suas } \\
\text { atribuições, coordena todo o } \\
\text { processo de informação que chega } \\
\text { aos níveis decisórios para que eles } \\
\text { a recebam com qualidade. }\end{array}$} & \multirow{6}{*}{ Silva e Gubert (2004) } \\
\hline $\begin{array}{c}\text { 7. Você acredita que conhecimentos das ferramentas de } \\
\text { Marketing de Relacionamento poderiam tornar o trabalho de } \\
\text { filtro de informação do secretário executivo mais eficiente? Por } \\
\text { quê? }\end{array}$ & & \\
\hline $\begin{array}{l}\text { 8. Enquanto gestor(a), você acredita que o secretário } \\
\text { executivo pode coordenar o processo de informação que chega } \\
\text { até você? Por quê? }\end{array}$ & & \\
\hline $\begin{array}{c}\text { 9. Especificamente quanto às informações do mercado e/ou } \\
\text { concorrência, você acredita que o secretário executivo pode } \\
\text { colaborar como um filtro, intermediando tais informações. Por } \\
\text { quê? }\end{array}$ & & \\
\hline $\begin{array}{c}\text { 10. Você acredita que conhecimentos de ferramentas de } \\
\text { Marketing de Relacionamento auxiliariam o secretário executivo } \\
\text { nessa função? Por quê? }\end{array}$ & & \\
\hline $\begin{array}{l}\text { 11. Em relação às informações dos clientes coletadas ao longo } \\
\text { dos contatos entre cliente e empresa, você acredita que o } \\
\text { secretário executivo pode colaborar como um filtro, } \\
\text { intermediando tais informações? Por quê? }\end{array}$ & & \\
\hline
\end{tabular}

Fonte: Desenvolvido pelos autores.

\subsection{Atribuições e competências do secretário executivo}

Observou-se que todos os entrevistados apontam como funções do secretário executivo não apenas atividades burocráticas, mas também atividades de apoio à gestão. Um 
dos entrevistados ilustra algumas dessas atividades: "Meu secretário executivo faz de tudo. Cuida da parte operacional. Desde o atendimento ao cliente, prospecção, faz a venda passiva e fecha o negócio". A fala de outro entrevistado reforça a importância do secretário executivo: "Cabe ao secretário da nossa empresa participar no processo de decisão". Isso corrobora com as ideias de Mazulo e Liendo (2010) e Silva e Gubert (2004), que colocam o secretário executivo como interface empresa-executivo e mercado-empresa, e que, na nova conjuntura, além de suas funções básicas, devem ajudar os executivos a colocar sua atenção no que é significativo para os negócios.

É interessante observar também que muitas das funções citadas pelos entrevistados aproximam a atividade do secretário executivo do trabalho de Marketing, como fica claro na fala de um dos entrevistados: "O secretário executivo na minha empresa trabalha na compilação de informações de concorrência, análise de dados das vendas do mês, anexa informações da matriz sobre o lançamento de algum produto. Ele entende os passos de execução de preço do produto em relação a concorrência". Para os entrevistados, há uma ligação muito forte do secretário executivo, não só com a parte de atendimento ao cliente, mas com toda a estrutura administrativa da empresa, atuando na compilação e divulgação interna das informações necessárias ao desenvolvimento otimizado dos negócios. Nesse sentido, um dos entrevistados destaca o atendimento ao cliente e outros três destacam o papel de secretário na busca, compilação e seleção de informações a serem transmitidas aos gestores. Como, segundo Barreto e Crescitelli (2013), o trabalho de Marketing deve focar em entender os clientes e adaptar-se da melhor forma possível a eles, a informação é parte central desse processo.

Por ter participação no fluxo de informação dentro da empresa e contato com o cliente, os dados obtidos com as entrevistas indicam que, conforme se levantou hipoteticamente, o trabalho do secretário executivo pode ter impacto na atividade de Marketing da organização. Além disso, segundo Barreto e Crescitelli (2013), todos aqueles que têm contato direto com o cliente deveriam ter conhecimentos básicos sobre Marketing de Relacionamento. Muitas tentativas de desenvolvimento de ações de Marketing de Relacionamento não dão certo por problemas de tecnologia de bancos de dados de clientes, mas o que leva o relacionamento ao fracasso é, na maioria das vezes, o engajamento dos funcionários (Barreto et al., 2013). Um dos entrevistados aponta que, se o secretário executivo tem contato direto com o cliente, ele também precisa estar envolvido com a atividade de Marketing de Relacionamento.

Três entrevistados destacam a necessidade de o profissional ter certas competências técnicas. Um deles elenca algumas competências que considera importantes: 'Um profissional que traga na bagagem algumas técnicas administrativas, algumas técnicas de $\mathrm{RH}$, técnicas de marketing, porque nós usamos tudo isso para compor o dia a dia da empresa". Ou seja, dentro das competências técnicas de um bom secretário executivo, a importância dos conhecimentos sobre Marketing surge novamente.

Um dos entrevistados aponta que é muito importante que o secretário executivo tenha bom relacionamento com as diversas áreas da empresa, para que assim haja uma efetiva comunicação com os clientes internos da organização: "O profissional tem que ter um extremo relacionamento com todas as áreas da empresa, saber se relacionar no ambiente interno e externo". Soma-se a essa descoberta a afirmação de Silva e Gubert (2004) de que essas relações são mais importantes em setores que demandam mudanças rápidas. Assim, é possível perceber a importância não somente das habilidades técnicas, mas também das habilidades humanas, especialmente em relação à comunicação e à sensibilidade para estabelecer a interação entre clientes, empresa e funcionários.

Todos os entrevistados concordam com a afirmação de que é necessário que o secretário executivo tenha uma ampla visão da empresa. A fala de um dos entrevistados ilustra isso: "Ter ampla visão da empresa e conhecer o que a empresa faz, conhecer o 
executivo e alinhar essas duas expectativas do que a empresa e executivo precisam é o maior desafio do secretário". Dois respondentes observam que, para o sucesso da empresa, é importante que aquele que de alguma forma intermedeia as negociações tenha conhecimento sobre todos os setores da empresa e esteja integrado aos processos para ter condições de intermediar de forma positiva e colaborar para que as expectativas sejam alcançadas.

A partir da resposta de um dos entrevistados, fica claro que um secretário executivo precisa conhecer um pouco de tudo dentro da empresa para que, dessa forma, haja total interação e harmonia na execução das tarefas: "O secretário é a ponte que liga todos os setores dentro da organização". Assim, o secretário cumprirá a missão de um executivo de serviços e despontará como base fundamental para a alavancagem de departamentos, setores e divisões da organização.

Um dos entrevistados afirma incentivar seu secretário executivo por meio de conversas e trocas de informações: "Nós conversamos muito sobre a situação do mercado. Meu secretário é muito informado". Outro entrevistado ressalta a importância do incentivo através de treinamentos, para que ele tenha cada vez mais instrumentos para colaborar com o desenvolvimento da empresa.

Por outro lado, os outros três entrevistados destacam que a iniciativa deve partir do próprio secretário. Para eles, no cenário contemporâneo, o profissional de Secretariado Executivo apresenta um novo perfil que está diretamente ligado a atitude pessoal. Ou seja, a empresa que não incentiva o funcionário já espera que essa competência esteja intrínseca ao trabalho dele. É possível perceber esse ponto de vista na fala de um dos entrevistados: "Se o secretário é um profissional que não tem atitude de integração, não tem atitude de relacionamento, e fica dependendo do incentivo da empresa é complicado".

Assim, é importante que o secretário coloque atenção nesse ponto, pois a empresa espera que o profissional possua essa iniciativa. Além disso, a empresa espera que o secretário executivo tenha uma visão do todo, sem que seja necessário ensiná-lo sobre a importância disso, como comenta um dos entrevistados: A iniciativa parte mais do funcionário. $\mathrm{O}$ profissional precisa conhecer o macro para ir para o micro". Isso reforça a afirmação de Rauber e Rauber (2013) de que um secretário executivo precisa ser versátil e competente para realizar diversas tarefas simultaneamente, destacando-se, nesse contexto, a visão sistêmica do profissional.

Nesse contexto, os incentivos na formação do secretário podem levá-lo a definir melhor os fatores de sucesso de sua equipe de trabalho, bem como a identificar os diferentes perfis e formas de adaptação. Assim, conhece melhor as diferentes missões de cada um e sabe intervir numa lógica de cooperação estabelecendo relações construtivas com toda a equipe.

\subsection{A importância das ferramentas de Marketing de Relacionamento}

Os entrevistados consideram ser benéfico que o secretário executivo tenha conhecimentos de Marketing de Relacionamento. A fala de um dos entrevistados ilustra essa posição: "É importante ter essa visão de Marketing de Relacionamento, e em especial as organizações que adotam um posicionamento estratégico de diferenciação". O profissional de Secretariado Executivo com visão global da organização e ciência das principais características do Marketing de Relacionamento pode atuar filtrando os pontos mais importantes que devem ser repassados ao executivo e influenciando as decisões de relacionamento com o cliente que serão repassadas aos demais funcionários da empresa.

Dois dos entrevistados destacam a importância de o secretário executivo atender e entender o cliente. Em uma das falas isso fica muito claro: "É fundamental que ele entenda a necessidade do cliente, que ele se coloque no lugar para entender o que realmente o cliente necessita". Para eles, é necessário entender a necessidade do cliente, ter empatia e se adaptar a 
ele. Esses pontos são a base do Marketing de Relacionamento para Pahins e Carvalho (2015), que acrescentam ainda a continuação na negociação com os mesmos clientes para manter e garantir o lucro das empresas.

No entanto, os outros três entrevistados afirmam que o Marketing de Relacionamento também se faz dentro da empresa, visto que o secretário executivo é peça importante para que haja uma comunicação eficiente entre todas as áreas da empresa. $\mathrm{Na}$ seguinte fala, isso fica claro: "O secretário depende de contatos dentro ou fora da empresa para solucionar qualquer tipo de problema".

É interessante observar também que os entrevistados concordam que cabe ao secretário executivo o gerenciamento cuidadoso de informações detalhadas sobre cada cliente e de todos os pontos de contato com ele. Isso maximizaria a fidelidade do cliente, o que inclui desde uma experiência em si até uma comunicação pessoal ou de massa, ou mesmo uma observação casual. Trata-se de proporcionar à empresa meios eficazes e integrados para atender, reconhecer e cuidar do cliente e da sua satisfação, como destaca um dos entrevistados: "Os conhecimentos de Marketing de Relacionamento ajudam a manter a confiança entre empresa e cliente".

\subsection{O secretário executivo como filtro de informações}

Todos os entrevistados concordam que o secretário executivo age como um filtro de informação na empresa e que existe uma percepção seletiva de informações, o que irá facilitar a informação que chegará ao executivo. O profissional precisará compilar as informações e ver o que realmente é necessário para aquele momento, como afirma um dos entrevistados: "Muita informação chega para o secretário, e tem uma questão ética envolvida, tem a questão de seleção de informações para passar para o executivo". Isso corrobora com a afirmação de Silva e Gubert (2004) de que uma das atribuições do secretário executivo é coordenar o processo de informação para que os níveis decisórios a recebam com qualidade e direcionada para soluções, decisões e resultados. Assim, pode-se dizer que o secretário funciona como um filtro das informações que chegam à empresa e, assim, pode sugerir as melhores atitudes para responder àquilo que o cliente necessita.

Um dos entrevistados, mesmo estando de acordo que o secretário executivo deva agir como um filtro de informações, considera que nem sempre é assim que acontece nas empresas: "No mundo ideal seria perfeito. Mas nem sempre o profissional chega na empresa pronto para ser esse filtro". Pressupõe-se que, se o Marketing de Relacionamento é um diálogo contínuo com o cliente, existe uma relação de aprendizado entre empresa e cliente que proporciona um atendimento personalizado e eficaz. Dessa forma, considera-se o gerenciamento das informações muito importante, pois é a base desse aprendizado. Se o secretário executivo age como um filtro de informação para o gestor, fica evidente o impacto do trabalho dele no Marketing de Relacionamento.

Todos os entrevistados acreditam que o conhecimento das ferramentas de Marketing de Relacionamento pode tornar o trabalho de filtro de informação do secretário executivo mais eficiente. Eles consideram que toda informação técnica nesse sentido se traduz em ponto positivo no trabalho do secretário executivo, além de ajudar para respostas mais rápidas na resolução de problemas. A fala de um dos entrevistados resume bem as opiniões dos demais: "É importante que o profissional tenha conhecimentos dessas ferramentas para poder identificar a necessidade do que ele precisa executar junto com o gestor dele, com as demais áreas da empresa e com os clientes".

Dois entrevistados destacam a importância de a empresa trabalhar os clientes mais importantes, selecionar as informações relacionadas a eles, e buscar manter um relacionamento de longo prazo com eles. Nesse sentido, o secretário executivo precisa ser 
capaz de identificar os clientes de maior valor para saber transmitir as informações ligadas a eles, como afirma um dos entrevistados: "O secretário dará mais atenção aos clientes mais importantes da empresa. Infelizmente, é uma questão de hierarquia”. Isso se alinha à afirmação de Barreto e Crescitelli (2013, p. 45) de que "as empresas devem identificar quais clientes são mais lucrativos ao longo de toda a relação com elas, focando suas ações de Marketing de Relacionamento neles".

Todos os entrevistados concordam que o secretário executivo pode e deve coordenar as informações que chegarão até o executivo da empresa. Um dos entrevistados é bem enfático nesse sentido: "Eu acredito que o secretário pode sim coordenar o processo de informação, e quanto mais eficiente ele é, melhor ele faz isso". Esse resultado remete à afirmação de Silva e Gubert (2004) que, dentro das atribuições de um secretário, está a de coordenar todo o processo de informação e colocar atenção no que é realmente significativo para os negócios da empresa.

\subsection{Outras funções do secretário executivo}

De forma geral, todos os entrevistados entendem que o secretário executivo tem impacto no sucesso de ações de Marketing de Relacionamento. Por consequência, as empresas que pretendam se engajar nessas ações devem exigir que seus secretários entendam os princípios básicos desse tipo de ação. É interessante observar também que muitas das funções apontadas pelos entrevistados aproximam a atividade do secretário executivo do trabalho de Marketing, especialmente na relação com os clientes.

Um dos entrevistados destaca o papel do secretário executivo no atendimento ao cliente: "O papel do secretário executivo dentro da organização é fazer a ponte e a melhor relação entre a empresa e o cliente". Outros três entrevistados destacam o papel dele na busca, compilação e seleção de informação a serem transmitidas aos gestores, funcionando como um filtro de informações do cliente. A seguinte fala de um dos entrevistados ilustra esse ponto: 'É importantíssimo que o secretário seja ouvido e procurado quando estamos falando da relação cliente $\mathrm{X}$ empresa. Aquela história de que diz que o secretário é o cartão de visita da empresa faz todo sentido, não no sentido figurado, e sim de ser a marca da empresa de alguma forma e saber coletar de melhor forma as informações que as empresas precisam trabalhar".

Outro ponto que é destacado por dois entrevistados é a importância do contato do secretário executivo com o cliente da empresa. Um dos entrevistados chega a colocar o secretário na função de ouvidor: "O secretário de certa forma, quando falamos da relação cliente X empresa, é como se ele fosse a ouvidoria da empresa". Isso tem impacto na percepção de qualidade da empresa por parte do cliente. Se o cliente se sente satisfeito, isso terá impacto direto no seu entusiasmo com a empresa e na intenção de se manter fiel como cliente.

\section{CONSIDERAÇÕES FINAIS}

Esta pesquisa teve como objetivo identificar a importância das ferramentas de Marketing de Relacionamento para os profissionais de Secretariado Executivo na perspectiva dos gestores na cidade de São Paulo. Assim, foi possível observar na análise das entrevistas que os conhecimentos técnicos do Marketing de Relacionamento aplicáveis ao secretário executivo contribuem para melhorar sua produtividade. Alinhado aos objetivos da empresa, o 
secretário executivo deve ser um profissional negociador, participativo, com um perfil empreendedor e capaz de colaborar na busca de excelentes resultados para empresa. Para isso, as ferramentas de Marketing de Relacionamento podem auxiliá-lo muito.

\section{Recomendações para a prática}

$\mathrm{Na}$ visão dos gestores entrevistados, o conhecimento de ferramentas básicas de gestão se torna cada vez mais útil para o aprimoramento do trabalho de Secretariado Executivo. Evidencia-se ainda que o domínio das principais funções administrativas e do Marketing de Relacionamento tornaram-se essenciais para o desenvolvimento do trabalho do secretário executivo, pois é muito importante que esses profissionais tenham as competências técnicas necessárias para reforçar a relação da empresa com o cliente.

Diante da relevância que os entrevistados atribuíram ao Marketing de Relacionamento no trabalho do secretário executivo, é necessário que os conteúdos referentes a essa ferramenta sejam revistos e atualizados desde a sua formação, para que ele disponha de instrumentos adequados. O secretário executivo atua como filtro de informação e tem contato direto com o cliente. Assim, para os entrevistados, o aprofundamento nos conteúdos relativos ao Marketing de Relacionamento dará ao profissional da área de Secretariado Executivo a possibilidade de exercer de forma aprimorada suas funções dentro da empresa, estando apto a atuar na linha de frente de uma organização e colaborar para os interesses dela.

\section{Limitações e sugestões para estudos futuros}

A natureza exploratória desta pesquisa permite um entendimento inicial sobre a importância das ferramentas de Marketing de Relacionamento para o profissional de Secretariado Executivo, contribuindo com a literatura ao relacionar dois temas que, até então, estavam pouco próximos. Ao mesmo tempo, justamente por se tratar de uma pesquisa exploratória e abordagem qualitativa, não é possível fazer inferências estatísticas ou relações de causa e efeito. Estudos futuros, utilizando outros métodos, são recomendados para aprofundar o entendimento sobre a relevância das ferramentas de Marketing de Relacionamento para o profissional de Secretariado Executivo. Realizar uma pesquisa com os secretários executivos permitiria também uma outra visão sobre o tema, enriquecendo a discussão aqui apresentada. 


\section{REFERÊNCIAS}

Azevedo, I. \& Costa, S. I. (2000). Secretária: Um guia prático. São Paulo: Senac.

Barreto, I. F. \& Crescitelli, E. (2013). Marketing de relacionamento: Como implantar $e$ avaliar resultados. São Paulo: Pearson Education do Brasil.

Barreto, I. F.; Crescitelli, E. \& Figueiredo, J. C. B. (2015). Resultados de Marketing de Relacionamento: Proposição de modelo por meio de mapeamento cognitivo. Revista Brasileira de Gestão e Negócios, 17(58), 1371-1389.

Berry, L. L. (1995). Relationship marketing of services: Growing interest, emerging perspectives. Journal of the Academy of Marketing Science, 23(4), 236-245.

Bíscoli, F. R. V. \& Lotte, R. I. (2006). Reflexões teóricas sobre a importância da comunicação na profissão de secretariado executivo. Revista Expectativa, 5(5), 157-172.

Biswas, S. (2016). Conceptual study of relationship signals in the IT services sector in India. Journal of Relationship Marketing, 15(3), 154-171.

Camargo, F. (2013). O homem e o secretariado. In B. D’Elia, M. Amorim \& M. Sita (Coords.), Excelência no Secretariado: A importância da profissão nos processos decisórios (pp. 62-68). São Paulo: Ser Mais.

Collis, J. \& Hussey, R. (2005). Pesquisa em administração: Um guia prático para alunos de graduação e pós-graduação (2a ed.). Porto Alegre: Bookman.

Decker, D. O (2010). A secretária como agente de qualidade. Revista de Gestão e Secretariado, 1(2), 5-31.

Denzin, N. K. \& Lincoln, Y. S. (2011). The Discipline and practice of qualitative research. In N. K. Denzin \& Y. S. Lincoln (Eds.), The SAGE handbook of qualitative research. (pp. 1-19). Thousand Oaks: SAGE Publications.

Gonçalves, S. T. (2007). A atuação do profissional graduado em Secretariado Executivo na área de marketing em grandes empresas na cidade de Belo Horizonte - MG. Dissertação de mestrado, Universidade Federal de Viçosa, Minas Gerais, Brasil.

Granero, A. E. (2008). Marketing de relacionamento. Franca: Uni-Facef.

Guimarães, M. E. (2001). O livro azul da secretária moderna (24a ed.). São Paulo: Érica.

Hair, J. F.; Babin Jr., B.; Money, A. H. \& Samouel, P. (2005). Fundamentos de métodos de pesquisa em administração. Porto Alegre: Bookman.

Khan, M. T. (2014). Relationship marketing: Some aspects (Review). International Journal of Information, Business and Management, 6(2), 108-122.

Malhotra, N. K. (2005). Introdução à pesquisa de marketing. São Paulo: Pearson Prentice Hall. 
Marshall, N. W. (2010). Commitment, loyalty and customer lifetime value: Investigating the relationships among key determinants. Journal of Business \& Economics Research, $8(8), 67-84$.

Martins, C. \& Zanon, M. (2013). A pesquisa na área do secretariado. In B. D’Elia, M. Amorim \& M. Sita (Coords.), Excelência no Secretariado: A importância da profissão nos processos decisórios (pp. 47-51). São Paulo: Ser Mais.

Mazulo, R. \& Liendo, S. (2010). Secretária: Rotina gerencial, habilidades comportamentais e planos de carreira. São Paulo: Senac.

Mendes, R. (2015). O que é Marketing de Relacionamento? Disponível em: http://www.pensandomarketing.com/home/id85.html

Neiva, E. G. \& D’Elia, M. E. S. (2009). As novas competências do profissional de secretariado. (2a ed.). São Paulo: IOB.

Pavoni, G. F.; Rocha, Q. C.; Vendrame, F. C.; Sarraceni, J. M. \& Vendrame, M. C. R. (2009). Marketing de relacionamento. Anais do II Encontro Científico e II Simpósio de Educação Unisalesiano, Lins, SP, Brasil.

Pahins, S. L. L. \& Carvalho, F. E. L. (2015). Comunicação e gestão de relacionamentos: O caso Fiat Mio. Anais do VIII Congresso Virtual Brasileiro de Administração, Brasil.

Payne, A. \& Frow, P. (2005). A strategic framework for customer relationship management. Journal of Marketing, 69, 167-176.

Peppers, D. \& Rogers, M. (2001). Marketing 1 to 1. (2a ed.). São Paulo: Makron Books.

Rauber, M. J. \& Rauber, A. S. (2013). Perguntar não ofende: Uma abordagem de coaching para o profissional de secretariado. Toledo: Mundo Hispânico.

Sheth, J. N. (2002). The future of Relationship Marketing. The Journal of Services Marketing, 16(7), 590-592.

Silva, R. S. M. \& Gubert, K. B. (2004). O Marketing de Relacionamento e sua influência para o profissional de Secretariado Executivo. Anais do XIV Congresso Nacional de Secretariado e IV Simpósio Internacional de Secretariado, Aracaju, SE, Brasil.

Zenone, L. C. (2010). Marketing de relacionamento: tecnologia, processos e pessoas. São Paulo: Atlas. 